\title{
Study and Evaluation of Aluminum Capsules to Irradiation of Gaseous Samples in Nuclear Reactor
}

\author{
Osvaldo Luiz da Costa ${ }^{*}$, Anselmo Feher, João A. Moura, Carla D. Souza, Rodrigo Tiezzi, Daiane C. B. de Souza, \\ Eduardo S. Moura, Henrique B. Oliveira, Carlos A. Zeituni and Maria Elisa C. M. Rostelato \\ Nuclear and Energy Research Institute - IPEN, Av. Professor Lineu Prestes, 2242 Cidade Universitária, São Paulo, SP, 05508-000, Brazil
}

\begin{abstract}
Gas irradiation in research nuclear reactors is an important way to produce radionuclides. Although some nuclear reactors centers offer this type of service, there are few publications about capsules to irradiation of gaseous samples. This paper describes a method to fabricate and evaluate aluminum capsules to irradiate gaseous samples in nuclear reactor. A semi-circular slotted die from a hydraulic presshead was modified to seal aluminum tubes. The aluminum capsules were subjected to leak detection tests, which demonstrated the accordance with standard ISO 9978.
\end{abstract}

Key words: Aluminum capsules, gas irradiation, ISO 9978, research nuclear reactor, tightness.

\section{Introduction}

The irradiation with neutrons is a relevant technique currently, as for radiopharmaceutical production as for scientific research. However, fewer nuclear centers in the world irradiate gas, such as McMaster Nuclear Reactor [1], McClellan Nuclear Research Center [2] and Bhabha Atomic Research Centre [3]. Also fewer publications about capsules to irradiation of gaseous samples are available [4]. More researches in this subject would assure an increase in safety and yield in gas irradiation. In the work reported here, a method to encapsulate gaseous samples is tested and evaluated. Firstly, an elementary pressure test was conducted to verify if the capsule resists the gas pressure without leaking, after an accurate trial with helium mass spectrometer demonstrate whether the capsule is according the standard ISO 9978 [5], which establishes the maximum leak rate for a gaseous sealed source.

\section{Materials and Methods}

The more common types of materials used to

\footnotetext{
*Corresponding author: Osvaldo Luiz da Costa, MSc., leading scientist, research fields: brachytherapy sources, iodine-125 production, iridium-192 production and iodine-125 seeds. E-mail: olcosta@ipen.br.
}

irradiate gas in nuclear reactors are aluminum, stainless steel and zircalloy. In this work, aluminum was chosen due to the following properties: low cost in relation to stainless steel and zircalloy, low neutron absorption cross-section, radionuclides produced are very short-lived (few minutes of half-life), good thermal conductivity, good machining, and it is possible to perform a tight container by cold welding without additional material $[2,6,7]$. The seamless aluminum alloy 6061 T6 tubing was selected because it has a good tensile strength $(310 \mathrm{MPa})$ and yield strength (276 MPa) [8]. The aluminum tubes have cylindrical shape, $9.5 \mathrm{~mm}$ (3/8 in.) outer diameter and $1.6 \mathrm{~mm}$ (1/16 in. wall thickness. Fig. 1 shows the aluminum capsule fabricated to irradiate gaseous samples beside standard aluminum rabbit used to irradiate solid samples in nuclear reactor IEA-R1.

A hydraulic presshead (crimping force $130 \mathrm{kN}$ ) connected to a hydraulic pump with a working pressure of 700 bar max (Cembre, RHC 131), was used to crimp the aluminum tubes. A semi-circular slotted die was modified to crimp without damage the aluminum tubes (Fig. 2). Three types of essays were used to determine the capsules tightness: pressure test with nitrogen gas, pressure test with hydraulic oil and helium mass 


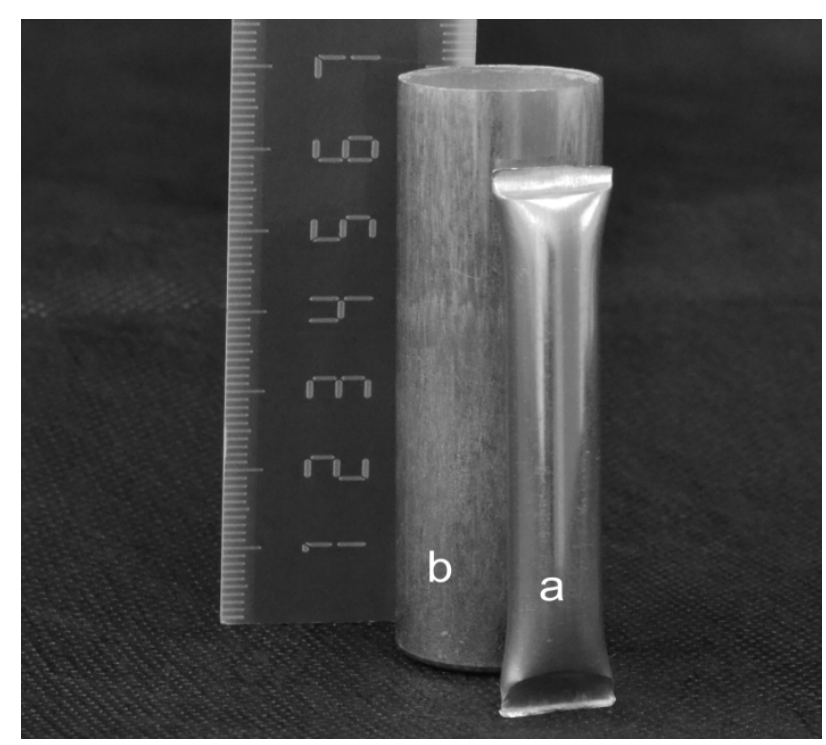

Fig. 1 (a) Aluminum capsule to irradiate gaseous samples and (b) standard aluminum rabbit used to irradiate solid samples in nuclear reactor IEA-R1.

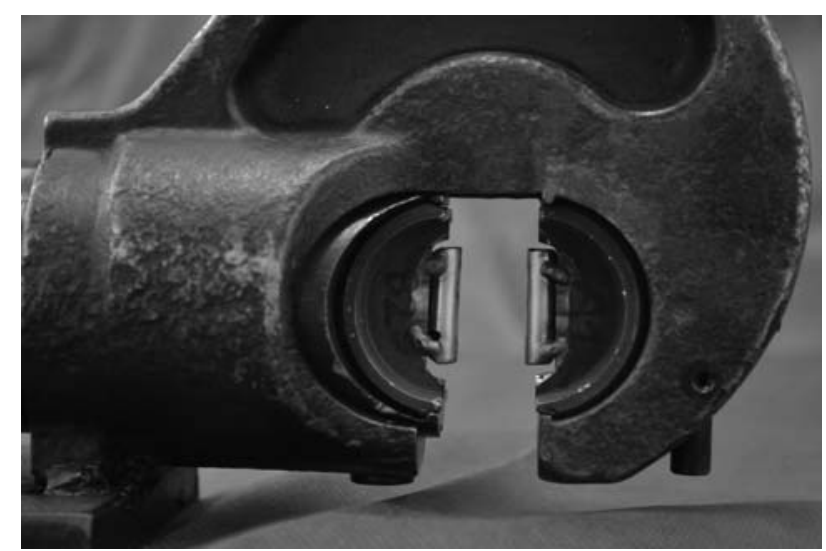

Fig. 2 Hydraulic presshead with semi-circular slotted die modified.

spectrometer leakage test [5].

The aluminum tubes were cut, a nut-ferrule set Swagelok tube fitting (brass, 3/8 in.) was assembled in one tube extremity, and another one was crimped by hydraulic presshead. The tube fitting was connected to a pressure regulator assembled in nitrogen gas cylinder. The internal pressure inside the tube was increased gradually with load bearing time of one minute and upward pressure. Soap bubble was used to leak detection.

The same fitting was used to connect the aluminum tube to hydraulic pump. The internal pressure was increased gradually with load bearing time of one minute and upward pressure. The leakage was detected when arose the formation of an oil drop on the crimping extremity.

The apparatus shown in Fig. 3 was manufactured in our laboratory to fill with helium gas. The capsules were tested in the helium mass spectrometer leak detector. First, the aluminum tube is connected to the valve $\mathrm{V} 5$, the vacuum pump is switched on and the valves V2, V4, V5 and V6 are opened. After that, the system is vacuumed $\left(6 \times 10^{-2} \mathrm{mbar}\right)$, the valve V6 is closed and the valve $\mathrm{V} 1$ is opened. The pressure regulator is used to fill the system with helium gas, with pressure between 1 and 3 bar. The presshead is used to crimp the capsule, which is ready to visual inspection and leak test. The visual inspections on the crimped area were made using an image inspection system (Westover Scientific, PV-VMZ4-IB), through the magnified images is possible to see small fissures, whereby the helium gas can escape, becoming the capsule inappropriate for helium leak test. A leak detector, Edwards model Spectron 3000, was used to determine helium leakage in the capsules.

Every helium mass spectrometer leak detector has an intrinsic stabilization time of signal. This time varies according the detector used [9]. The signal stabilization time was verified by means of three measurements without any sample inside the test chamber of mass spectrometer (Fig. 4). The variations in the early $6 \mathrm{~s}$ are caused by the opening of test chamber, vacuum stabilization inside test chamber and changes was in the leak detector vacuum system searching the best grade of measurement. The signal was stabilized at a value $\sim 2 \times 10^{-10} \mathrm{~Pa} \cdot \mathrm{m}^{3} \cdot \mathrm{s}^{-1}$ after $6 \mathrm{~s}$.

\section{Results and Discussion}

Fig. 5 shows that the crimped extremity on the aluminum tubes through the image inspection system. Fig. 5a presents a crimping without failure, there is not signal of fissures. Fig. $5 \mathrm{~b}$ presents a fissure on the crimping surface, factors as a misalignment between the semi-circular slotted dies, or a tubing wall thickness 


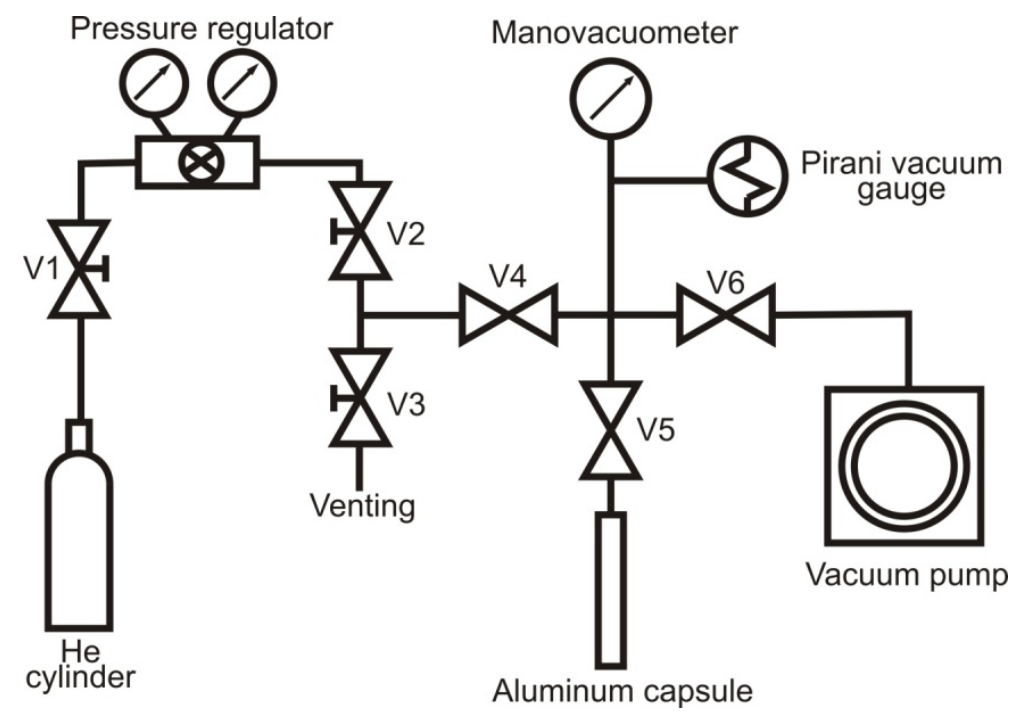

Fig. 3 Scheme of helium filling.

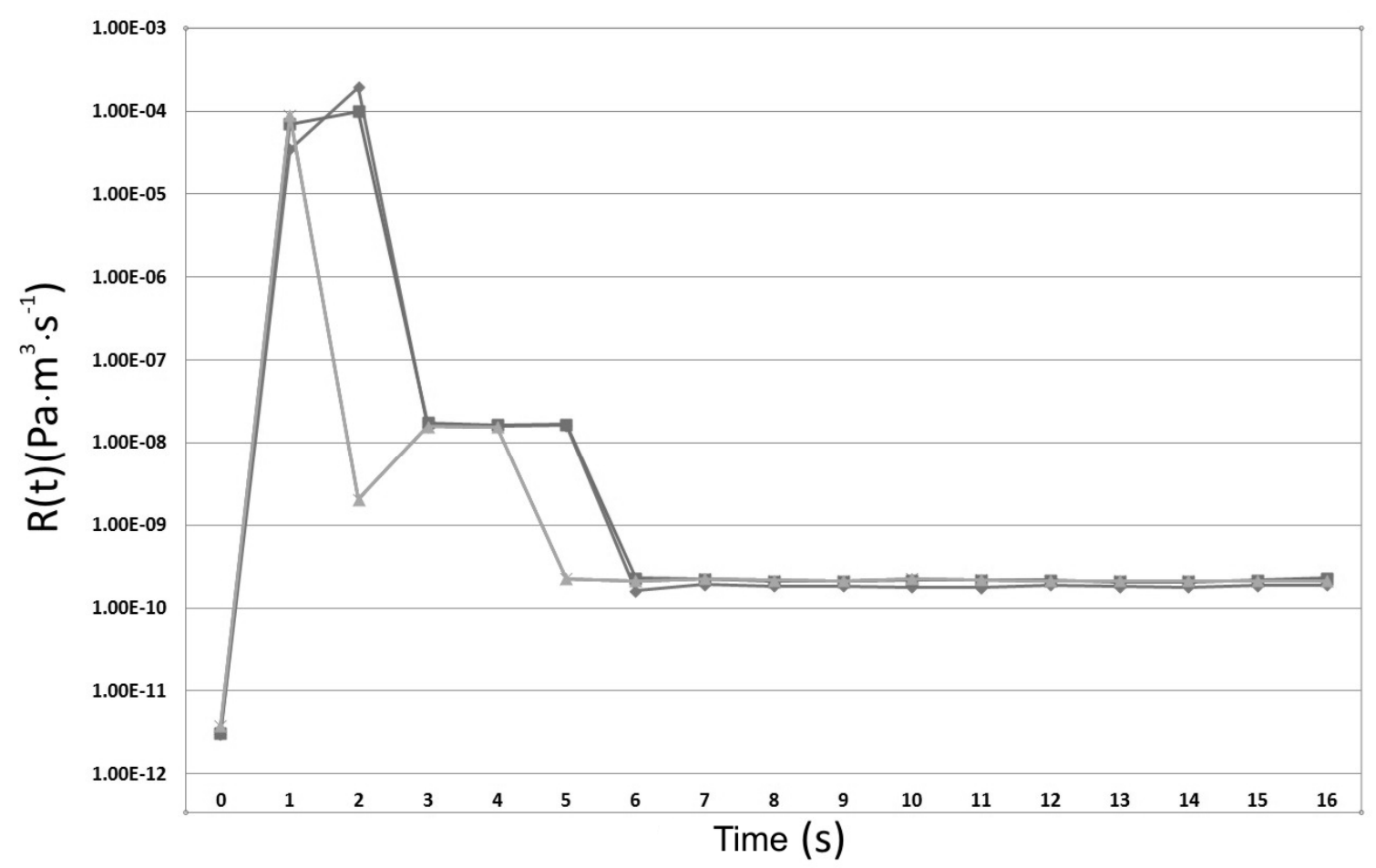

Fig. 4 Mass spectrometer stabilization time.

lower than the specified may cause this type of defect. Replacing the aluminum alloy by another as the 3003 (tensile strength 110-175 MPa, yield strength 42-175 $\mathrm{MPa}$ ) or the 1050 (tensile strength 76-131 MPa, yield strength 28-124 MPa) may decrease the quantity of this kind of failure. However, the limit pressure likely would decrease also [8]. The tubes whose crimping presented fissures were discharged.

All the crimped tubes tested with nitrogen pressure supported until 22.5 bar (the limit of the system), without leakage. This simple and practical test may be used to know if a method to seal containers is adequate or not, by this way, we can select the best methods to more accuracy tests. 
All the crimped tubes tested with the hydraulic pump resisted pressure until approximately 75 bar.

The International Standard ISO 9978 - Sealed radioactive sources - Leakage test methods [5] was used as reference to guarantee the leak tightness provided by the sealing process. The standard ISO 9978 establishes for radioactive sealed sources with leachable or gaseous contents, maybe applied the following tests: helium test, helium pressurization test and liquid nitrogen bubble test. The limiting value to the helium leak rate to these sources is $10^{-2} \mu \mathrm{Pa} \cdot \mathrm{m}^{3} \cdot \mathrm{s}^{-1}$. A leakage rate of $10^{-1} \mu \mathrm{Pa} \cdot \mathrm{m}^{3} \cdot \mathrm{s}^{-1}$ for leachable and gaseous contents would, in most cases, be considered to be equivalent to the activity release limit of $2 \mathrm{KBq}$ [5].

Eleven aluminum capsules samples filled with helium, pressure between 1 and 3 bar, sealed by the crimping method, were tested. The Fig. 6 shows the leak rate of aluminum capsules, the measurements were started $20 \mathrm{~s}$ after the beginning of leak detection because the stabilization time of signal. All the analyzed samples stayed in a range close to $1 \times 10^{-10}$ $\mathrm{Pa} \cdot \mathrm{m}^{3} \cdot \mathrm{s}^{-1}$, which is a result 100 times below the maximum release limit of $1 \times 10^{-8} \mathrm{~Pa} \cdot \mathrm{m}^{3} \cdot \mathrm{s}^{-1}$ established in the standard ISO 9978.

\section{Conclusions}

In this study, we fabricated and tested sealed aluminum capsules to irradiate gaseous content in research nuclear reactor. The first pressure test, increasing the internal pressure, verifies, in a simple way, the viability of the sealing process. If the sealing process passes in the first test, capsules filled with

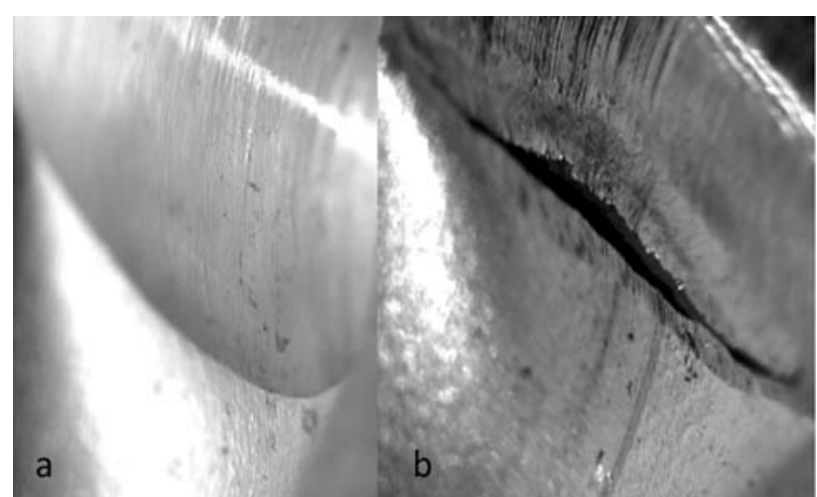

Fig. 5 Aluminum tube crimping area (a) without fissure and (b) with fissure.

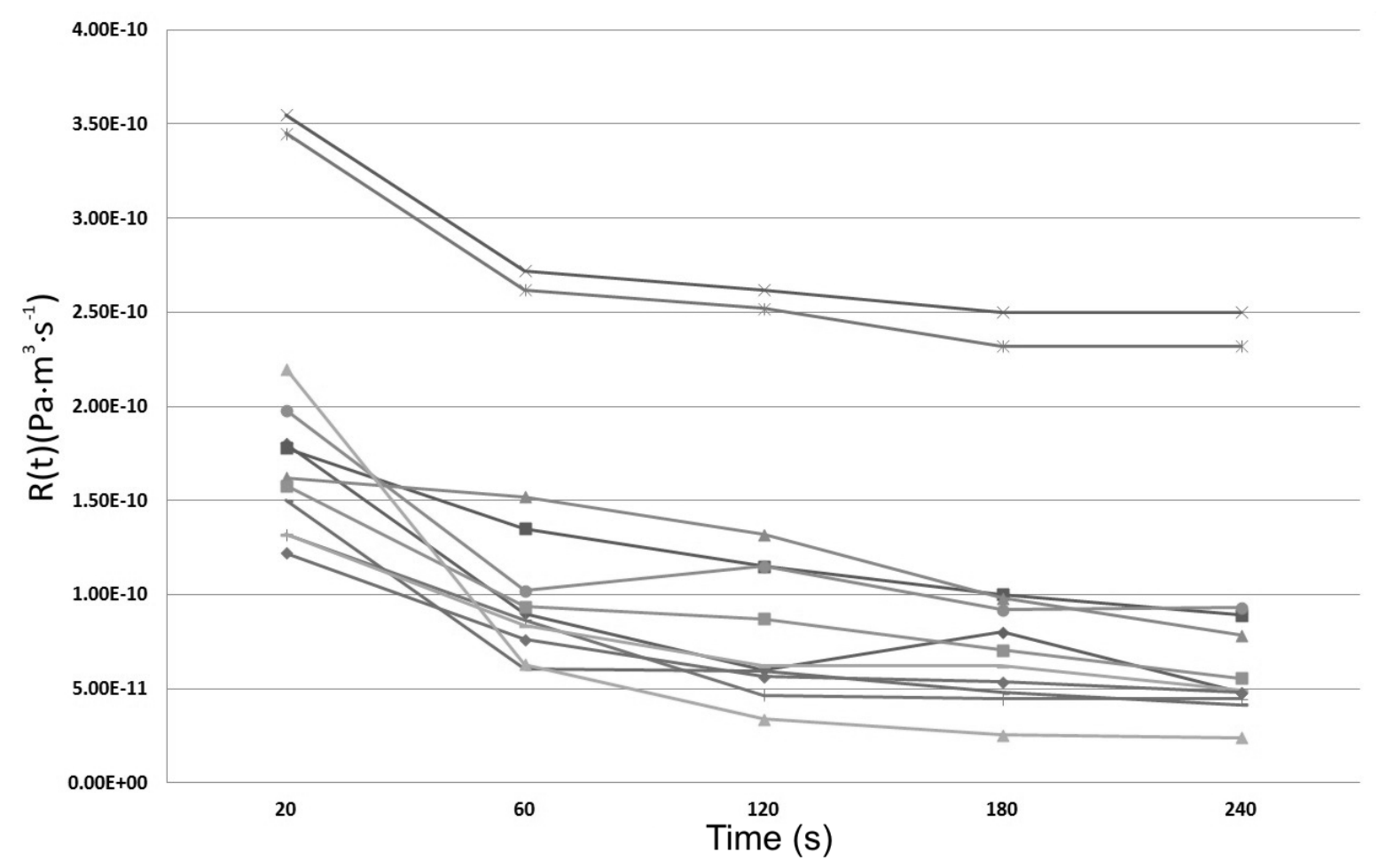

Fig. 6 Leak rate of $\mathbf{1 1}$ aluminum capsules obtained from helium mass spectrometer. 
helium maybe prepared to the second test with helium mass spectrometer leak detector. The aluminum capsules fabricated and evaluated in the present study resisted until pressure of 75 bar and demonstrated to obey the leaktight standard established by ISO 9978, staying 100 times below the maximum release limit, therefore, the capsules can be used to irradiate gaseous samples in nuclear reactors with an excellent safety factor for samples between 1 and 3 bar. Besides, the aluminum presents good characteristics, as thermal transfer and low cross-section for neutrons, which become it an excellent material as irradiation capsule for nuclear reactor. The fabrication methods of capsules to irradiation with neutrons in research nuclear reactor must be carefully elaborated and tested. The irradiation of leachable and gaseous contents further increase the safety characteristics applied to these methods. Despite being an extreme importance area for scientific research with nuclear reactors, there are fewer articles available about the theme. The repetitive use of cylinders purchased in the market it is the more common procedure.

In future paper, other aluminum alloys maybe tested and compared in relation to pressure resistance, cost, produced radionuclides, leaktightness, capsule radioactivation and chemical inertness.

\section{References}

[1] ASM International. 1992. Properties and Selection: Nonferrous Alloys and Special-Purpose Materials. ASM International Handbook Committee. ASM Handbook. v. 2

[2] Han, B. 2012. "Measurements of True Leak Rates of MEMS Packages." Sensors 12: 3082-104.

[3] International Atomic Energy Agency. 2003. Manual for reactor produced radioisotopes. IAEA, IAEA-TECDOC-1340.

[4] International Organization for Standardization. 1992. Sealed Radioactive Sources - Leak Test Methods. (ISO 9978-1992).

[5] Kar, A. 2007. "Novel ${ }^{125}$ I Production and Recovery System." Master of Science thesis, Texas A\&M University.

[6] Kim, H. I., Park, U. J., Jun, B. J. and Han, H. S. 2006. "Internal Circulating Irradiation Capsule for Iodine-125 and Method for Producing Iodine-125 Using Same. Korea Atomic Energy Research Institute. US Pub. 2006/0126774.

[7] Hassal, S. B. 2000. "Method and Apparatus for Production of Radioactive Iodine." McMaster University US 6056929.

[8] Lagunas-Solar, M. C., Steingass, W. G., Liu, H. B. and Boussoufi, M. 2011. "Iodine 125 Production System and Method." University of California. WO 2011/063355 A2.

[9] Venkatesh, M. and Banerjee, S. 2007. "Chemical Sciences \& Engineering - BARC Highlights.” Bhabha Atomic Research Centre, 18-9. 